\title{
ENTENDIMENTOS SOBRE NATUREZA E NÍVEIS DE CONEXÃO COM A NATUREZA ENTRE PROFESSORES/AS DA EDUCAÇÃO BÁSICA
}

\author{
Damaris Teixeira Paz \\ Instituto Nacional de Pesquisas da Amazônia \\ Maria Inês Gasparetto Higuchi \\ Instituto Nacional de Pesquisas da Amazônia \\ Dayse da Silva Albuquerque \\ Instituto Nacional de Pesquisas da Amazônia \\ Adria de Lima Sousa \\ Instituto Nacional de Pesquisas da Amazônia \\ Antonio Roazzi \\ Universidade Federal de Pernambuco
}

\begin{abstract}
Resumo
Os benefícios que a conexão com a natureza traz para crianças e adolescentes têm sido confrontados com evidências do crescente distanciamento dos ambientes naturais destes grupos, principalmente nas grandes cidades. A escola poderia ser um meio para reduzir esse distanciamento, a partir da mediação dos/as professores/as. Entre tantos aspectos presentes nessa situação, pouco se problematiza como os/as professores/as compreendem a natureza e a necessária reconexão. Este estudo buscou, portanto, verificar os entendimentos sobre a natureza e da conexão com a natureza entre professores/as da educação básica numa região onde ela está presente de forma exuberante. A pesquisa de abordagem qualitativa foi realizada com a aplicação de um formulário com perguntas fechadas e abertas e escalas sociais tipo likert. Participaram do estudo 150 professores/as de escolas públicas da cidade de Manaus/AM. Os resultados obtidos por meio de análise de conteúdo e estatística não paramétrica demonstram diferentes entendimentos sobre natureza e estados de conexão com a natureza. Observou-se ainda que o gênero, idade e área de formação são variáveis determinantes na intensidade da conexão com a natureza.
\end{abstract}

Palavras-Chave: Conexão com a Natureza; Afetividade ambiental; Afinidade emocional;

\section{Abstract}

The benefits that connections with nature brings to children and adolescents have been confronted with evidence of the growing distancing of the nature of these groups, especially in large cities. The school could be a means to reduce this distance, from the teachers' mediation. Among so many aspects present in this situation, there are few studies focusing on how the teachers are supportive of those emotional ties for this necessary reconnection via the school curriculum. This study, therefore, sought to verify such understandings among elementary school teachers in a region where nature is present exuberantly. A form with closed and open questions and social Likert-type scales was used in this study to 150 teachers from public schools in the city of Manaus/AM. The results obtained through content analysis and statistical tests demonstrate that the different understandings of nature and what teachers understand to be connected to it, along with gender, age, and graduation area, are key variables in the intensity of emotional affinity toward nature.

Keywords: Connections with Nature; Environmental Affectivity; Nature Emotional Affinity

ISSN 1645-1384 (online) www.curriculosemfronteiras.org

http://dx.doi.org/10.35786/1645-1384.v20.n3.19 


\section{Introdução}

O estilo de vida frenético das grandes cidades tem se apresentado como produtor de desgastes para as pessoas em múltiplos níveis, seja emocional, cognitivo, social ou físico (FAJERSZTAJN; VERAS; SALDIVA, 2016; GÜNTHER; FRAGELLI, 2011; SALDIVA, 2018). Compreender os aspectos que podem trazer um alento a essas condições de desconforto ou até de sofrimento, torna-se necessário para o desenvolvimento de programas interventivos mais eficazes em busca de uma melhor qualidade de vida e proteção ambiental (CHENG; MONROE, 2012). Uma maior aproximação com a natureza é uma dessas possibilidades alentadoras. Os benefícios advindos do contato com a natureza têm ganhado notoriedade revelando que é possível investir em espaços de vida mais verdes e saudáveis contribuindo para um efetivo cuidado dela e a promoção da qualidade de vida das pessoas (ALVES, 2011), além de que laços afetivos de apego à natureza se distinguem na defesa de áreas verdes (SOUSA et al., 2015). Além disso, incentivos de uso e aproximação desses espaços devem ser empreendidos de forma mais eficiente na sociedade atual, inclusive como proposta curricular nas escolas de educação básica. Considera-se que tais situações possam ser reveladoras nas relações pessoa-ambiente, mais particularmente, pessoa-natureza, propiciando maior cuidado ambiental e melhoria de bem-estar integral dos/as citadinos/as.

Nesse âmbito, a Psicologia Ambiental, como campo que busca o aprofundamento dos aspectos da relação pessoa-ambiente, traz o conceito de Conexão com a Natureza $(\mathrm{CN})$ para caracterizar a ligação emocional das pessoas com o mundo natural, sejam elas adultas (FRANTZ; MAYER, 2014; MAYER; FRANTZ, 2004) ou crianças (CHENG; MONROE, 2012). É uma perspectiva promissora para compreender a intenção e a efetiva ação que se qualifique como base para um comportamento pró-ambiental. Isto é, à medida que a pessoa sente-se bem em determinado espaço, em função de suas áreas verdes que propiciam contato com a natureza, é possível que esta pessoa desenvolva ações de cuidado e proteção ao ambiente, bem como ações que envolvam comportamentos sustentáveis e que diminuam o impacto ambiental causados em alguma proporção (CORRAL-VERDUGO, 2012). A dimensão afetiva das atitudes é vital tanto para saúde integral quanto para a proteção ambiental.

A afinidade emocional com a natureza pode ser associada à biofilia, termo utilizado para explicar a predisposição humana a reconhecer benefícios e recompensas a partir do contato com elementos naturais (FEDRIZZI, 2011; MARTIN; CZELLAR, 2017). Além disso, essa afetividade aproxima-se da concepção de apego ao lugar (SCANNELL; GIFFORD, 2010) ao englobar aspectos afetivos mediados por experiências pessoais e coletivas com o ambiente que culminam em crenças e valores compartilhados a nível social (VERISSIMO, 2013). Estudos mostram que aspectos cognitivos e afetivos se apresentam como fatores cruciais de atitudes em prol da responsabilidade e cuidado ambiental (FISHBEIN; AJZEN,1975; KALS; MAES, 2008; STERN; DEITZ, 1994) ou da falta dele (GIFFORD, KORMOS; MCINTYRE, 2011). Quanto maior o grau de $C N$ ou afinidade que uma pessoa tiver, maior também é a possibilidade dessa pessoa ter um comportamento de cuidado ambiental (COELHO et al., 2017; NISBET; ZELENSKI; MURPHY, 2011). 
Assim, ao considerar os aspectos cognitivos e afetivos que constituem a relação pessoanatureza, questiona-se como esses posicionamentos frente à natureza, ou como tal $\mathrm{CN}$ se manifesta no indivíduo. Ou seja, quais os elementos que concorrem para a formação dessa afinidade com a natureza? Pesquisadores/as que se dedicam a essa trajetória envolvendo a afetividade direcionada ao ambiente apontam que esta ocorre tanto pela psicogênese como pela sociogênese, porém esta última parece ser mais saliente e preponderante na efetiva manifestação do comportamento (BOFF, 2003; GUATARRI, 2001). Estudos direcionados ao entendimento desse constructo entre pessoas adultas enfatizaram o papel vital que as experiências positivas com e na natureza (trilhas, acampamento, caminhadas, passeios etc.), durante a infância tiveram na orientação e envolvimento em atividades socioambientais (CHAWLA, 2007; HUGHES, RICHARDSON; LUMBER, 2018; LOUV, 2016). Nesse sentido, as experiências vivenciadas ao longo do desenvolvimento podem ter um papel importante na construção de laços de afinidade emocional com o ambiente.

Considerando o importante papel da escola na formação de cidadãos e cidadãs, em parceria com a família, é notório esperar desse segmento estímulos concretos de aproximação com os ambientes naturais. Isso representa enfatizar os benefícios por meio de vivências no contato direto durante a atividade escolar, ou de modo indireto, pela ênfase e reconhecimento dessa atividade de encontro com a natureza em momentos fora da sala de aula. Esses exemplos, junto com outras tantas possibilidades podem se constituir genuínos aspectos para formar atitudes pró-natureza.

As atitudes em relação à natureza apresentam-se como condutores de interesse científico, uma vez que a questão ambiental envolve uma complexidade inerente ao âmbito coletivo e não apenas individual (CASTRO, 2005; IVES et al., 2017). Sem a intenção de menosprezar os aspectos internos que estão atrelados à manifestação da afetividade, este estudo procurou verificar quais os entendimentos dos docentes sobre natureza e sua percepção de CN. Ao evidenciar esses entendimentos e níveis de $\mathrm{CN}$ dos/as professor/as, é possível compreendermos as implicações na forma de abordagem desse tema junto aos educandos. Atitudes de afetividade com o mundo natural podem culminar em práticas transformadoras mediadas por docentes que demonstrem e transmitam essa relação de reciprocidade com a natureza (OTTO; PENSINI, 2017; TOLEDO; PELICIONI, 2006).

\section{Natureza: Cognição e Afetividade}

A natureza assume tanto uma dimensão real quanto simbólica. Real porque, por um lado, pressupõe elementos concretos que podem ser vivenciados a partir da experiência com o corpo, fonte de todo conhecimento perceptivo genuíno. Por outro lado, essa mesma concepção assume uma dimensão simbólica a partir dos significados representados e compartilhados mediante a intersubjetividade presente no mundo vivido (MERLEAUPONTY, 1999). A cognição sobre natureza e a afetividade sentida passam a ter um papel fundamental no modo como nos relacionamos com ela. 
A dimensão cognitiva sobre a natureza deriva de informações elaboradas de forma espontânea ou mediada por outras pessoas nas mais diversas vivências, formando um constructo que estará subjacente a um conjunto imensurável de comportamentos. Dessa maneira, a capacidade que as pessoas possuem de conhecer, armazenar e extrair informação a partir das interações estabelecidas com o ambiente físico e social contribui para novas transformações ambientais (HIGUCHI; KUHNEN; BOMFIM, 2011). A dimensão afetiva relaciona-se com os aspectos cognitivos na medida em que as crenças a respeito de algo implicam em associações valorativas que indicam sentimentos a partir de experiências mediadas pela cognição. A potência da dimensão afetiva reside justamente nessa unidade entre pensamento e sentimento como forma de ampliação da consciência e como potencial de transformação (BRANDÃO, 2012; MOURTHE JUNIOR; LIMA; PADILHA, 2017). Portanto, não é possível dissociar os aspectos afetivos dos cognitivos dada a relação dialógica, recursiva e hologramática entre eles (MORIN, 2008).

A afetividade, no entanto, tem caráter distintivo nas ações de afinidade com os ambientes naturais que leva a um senso de aproximação e valorização positiva e integrada (BOMFIM, 2010). A natureza tem sido evidenciada como elemento desencadeador de sentimentos positivos em diversos estudos realizados nos Estados Unidos e Europa, países que sofrem os impactos negativos da degradação dos recursos naturais e do estilo de vida em grandes metrópoles (DAVIS; GREEN; REED, 2009; PERRIN; BENASSI, 2009). Todavia, os estudos realizados no Brasil ainda não foram suficientes para afirmar essa relação de afinidade com a natureza (WHITBURN; LINKLATER; ABRAHAMSE, 2019) e até mesmo evidenciam o contrário, ou seja, certa desvalorização quanto mais próxima ela se encontra (ALBUQUERQUE; SILVA; KUHNEN, 2016; CUNHA, 2010; GÜNTHER et al., 2003). Isso pode ocorrer devido a fatores históricos culturais se compreendermos o Brasil como país continental que, ainda que em desenvolvimento com grandes metrópoles, possui a natureza muito mais em evidência quando comparado com países desenvolvidos, nos quais os estudos sobre os benefícios da aproximação com ela têm sido realizados (DIEGUES, 2011; GRESSLER, 2014; GRESSLER; GÜNTHER, I. 2013).

Diante de diferentes compreensões de natureza que abarcam cognição e afetividade como unidade, estudos têm revelado ainda, que ela quando passa a ser sacralizada permite um senso de conexão, de tal modo que pessoa e ambiente sentem-se um só (CARVALHO; STEIL, 2012). Todavia esse sentido de conexão só é possível a partir da experiência com o corpo, de uma interação real e não mediada. Portanto, verificar a afinidade emocional em relação à natureza, com agentes que exercem um fundamental papel de inspiração e construção de cidadãos/ãs, como os/as professores/as, se torna um fator relevante para indicar novos caminhos para a educação e para as questões ambientais que são invariavelmente sociais.

Nesse sentido, o estudo foi norteado por questões como: Quais os entendimentos sobre natureza e aspectos constitutivos de conexão com a natureza de professores/as da educação básica de escolas da rede pública de uma cidade incrustada na floresta amazônica? Esses aspectos cognitivos estariam implicados nos níveis de conexão, ou seja, nos níveis de afinidade emocional estabelecidos com a natureza? Teriam estes/as professores/as laços 
afetivos com a natureza? Neste estudo mostra-se, portanto, aspectos de entendimento sobre o constructo natureza e conexão com a natureza entre esses/as professores/as, ao mesmo tempo em que se estabelecem seus respectivos níveis de CN. Evidencia-se ainda alguns aspectos coadjuvantes desta atitude que atrai/aproxima ou afasta/distancia esses/as professores/as na relação afetiva com os ambientes naturais.

\section{Método}

Esse estudo se deu a partir de uma abordagem multimétodos (GÜNTHER; ELALI; PINHEIRO, 2011), cujo questionário aplicado incluiu perguntas abertas e fechadas sobre o perfil dos participantes e duas escalas sociais de afinidade emocional. A Escala de Conexão com a Natureza (ECN), proposta por Mayer e Frantz (2004), e a Escala de Inserção da Natureza no Self (INS), proposta por Schultz (2001), foram utilizadas neste estudo tendo em vista sua capacidade de medir a $\mathrm{CN}$ e já terem sido usadas em estudos para população brasileira (PESSOA et al., 2016; ROSA et al., 2015).

\section{Participantes}

Participaram da investigação 150 professores, sendo 84 mulheres e 66 homens, com idade entre 23 e 61 anos. A seleção das 23 escolas baseou-se na distribuição por zonas utilizada pelas Secretarias de Educação e a participação dos/as professores/as ocorreu a partir da acessibilidade permitida pelos/as gestores/as.

Foram selecionadas apenas escolas públicas (estaduais e municipais), que atendiam ao ensino fundamental 2 e ao ensino médio, com a participação de cinco a sete professores/as por escola. Entre os/as professores/as, 32 são graduados/as em áreas das Ciências da Natureza (Ciências Biológicas, Ciências Naturais, Geografia, Física), 36 em áreas das Ciências Humanas (Filosofia, Normal Superior, Pedagogia, História, Artes, Música), 24 são formados/as em Matemática, 41 em Letras (Língua Portuguesa ou Estrangeira) e 17 em Educação Física. Desse total, 89\% lecionam disciplinas que estão de acordo com a sua formação e os demais $11 \%$ tem uma ou mais disciplinas sob a sua responsabilidade que não estão de acordo com a sua formação.

\section{Instrumentos e Procedimentos}

Um dos instrumentos mais utilizados tem sido a Escala de Conexão com a Natureza (ECN) proposta por Mayer e Frantz (2004) como forma de mensurar o nível de ligação emocional entre a pessoa e o mundo natural. Segundo os autores, a ECN pode servir como instrumento indicativo do comportamento ambiental.

A ECN contém 14 itens $^{1}$, com graus de concordância variando de 1 - discordo plenamente a 5 - concordo plenamente. Os graus de concordância correspondem conjuntamente na escala a um escore no qual o cinco representa alta conexão com a natureza 
e o um representa baixa conexão (MAYER; FRANTZ, 2004). A ECN permite verificar a relação entre os sentimentos possíveis direcionados a natureza no modo como conduzem suas afirmativas diante das questões expostas. Estas permitem uma reflexão quanto a ideias que apontam para uma predisposição positiva e integradora com os elementos naturais (FEDRIZZI, 2011), bem como ideias antropocêntricas (MARTIN; CZELLAR, 2017; THOMPSON; BARTON, 1994). A Escala de Inserção da Natureza no Self (INS), adaptada a partir do trabalho de Schultz (2001) contém sete diagramas que representam níveis graduais de conexão da natureza com o self (anéis que no menor grau são dispostos paralelamente e no maior grau se interpõem de tal forma que apenas um anel é visto, mostrando total interface entre o self e a natureza). O diagrama número um representa pouca conexão e o número sete uma conexão total com a natureza. Ao analisar tais anéis os/as professores/as circulavam o que melhor representava sua condição. Essas escalas têm sido utilizadas no Brasil e vêm sendo adaptadas para melhor mensurar a afinidade emocional com a natureza em pessoas adultas nesse país (GRESSLER, 2014; ROSA, 2014; PESSOA et al., 2016).

O projeto foi submetido ao Comitê de Ética em Pesquisa com Seres Humanos e aprovado sob parecer $\mathrm{n}^{\circ}$. 665.340. Os instrumentos de coleta foram aplicados individualmente aos professores/as na escola onde atuavam e teve duração média de 15 minutos. As respostas provenientes das questões abertas sobre o entendimento de natureza e do que seria estar conectado a ela foram submetidas a análise de conteúdo (BARDIN, 2004; BAUER, 2010). A análise de conteúdo inicia-se a partir do processo de pré-análise, ou seja, organização dos dados, seguido pela exploração do material e, finalmente, o tratamento dos resultados, a inferência e a interpretação. Por fim, os dados são classificados em unidades de significação, o que resulta em categorias. Essa análise permitiu vislumbrar as categorias que emergiram em função do entendimento de natureza e do que seria estar conectado à ela.

Para efeito de correlações, tais categorias nominais foram codificadas numericamente. Os dados referentes aos graus atribuídos às afirmativas contidas nas escalas, foram inseridos numa planilha do software Excel e transportadas para o SPSS (Statistical Package for Social Sciences) para as análises estatísticas das médias e testes de correlação.

\section{Resultados e Discussão}

Considerando que o estudo inclui análises qualitativas que geraram categorias e posteriormente foram submetidas a testes de correlação, problematiza-se inicialmente as categorias advindas dos entendimentos cognitivos a respeito de natureza e conexão com a natureza, respectivamente. A seguir apresenta-se o grau de afinidade emocional e demais variáveis associadas juntamente com a discussão de tais resultados. 


\section{Entendimentos de natureza}

A análise de conteúdo revelou quatro categorias cognitivas de natureza atribuídas pelos/as professores/as: (1) ambiente ecocêntrico; (2) ambiente biocêntrico; (3) ambiente restaurador e, (4) ambiente divino. Cada uma dessas categorias revela um tipo de entendimento com nuances diferenciadas da relação das pessoas com a natureza, refletindo uma maior aproximação ou distanciamento dos elementos que a compõem. A Tabela 1 mostra a distribuição das respostas de acordo com essas categorias.

Tabela 1: Descrição das categorias de entendimento sobre o termo natureza e frequências

\begin{tabular}{l|c}
\multicolumn{1}{c|}{ Categorias de entendimento de Natureza } & $\mathbf{N}$ \\
& $\%$ \\
\hline $\begin{array}{l}\text { 1. Ambiente ecocêntrico: Natureza como parte de um todo, constituinte de um ecossistema } \\
\text { de relação de todos os seres humanos e não humanos, um cosmo, uma gaia, unidade } \\
\text { substancial para o equilíbrio e existência da vida no planeta e que, portanto, deve ser } \\
\text { preservada e cuidada. }\end{array}$ & 39 \\
\hline $\begin{array}{l}\text { 2. Ambiente biocêntrico: Natureza como ambiente natural, rústico e primitivo, fonte de } \\
\text { recursos para os humanos onde encontramos rios, animais, ar puro e plantas e florestas que } \\
\text { formam um ecossistema natural que permite o equilíbrio e contemplação dos humanos. }\end{array}$ & 36 \\
\hline $\begin{array}{l}\text { 3. Ambiente restaurador: Natureza como fonte que promove o bem-estar, saúde, } \\
\text { tranquilidade e restauradora do equilíbrio emocional das pessoas; inspiradora de bons } \\
\text { sentimentos e experiências vividas com suas paisagens e elementos naturais. }\end{array}$ & 20 \\
\hline $\begin{array}{l}\text { 4. Ambiente divino: Natureza como uma criação divina, algo perfeito que remete à existência } \\
\text { e grandeza de um Deus que presenteou os humanos, pela qual todos devem zelar. }\end{array}$ & 5 \\
\hline TOTAL & 100 \\
\hline
\end{tabular}

\subsection{Ambiente ecocêntrico}

Essa categoria apresenta a natureza como uma unidade constituinte de um ecossistema de relação de todos os seres humanos e não humanos, um cosmo, uma gaia, unidade substancial para o equilíbrio e existência da vida no planeta e que, portanto, deve ser preservada e cuidada. Esse entendimento esteve presente nas respostas de 39\% dos participantes que afirmam que "(...) relação entre homem e os seres que nos cercam, não só animais, mas também plantas e a biodiversidade" e que sendo uma unidade deve primar por "[uma] união de todos os seres existentes, relacionando-se com o objetivo de manter equilibrio".

Essa compreensão assemelha-se à de homem na biosfera descrita por Cortez (2011), pois já considera o ambiente sendo constituído por dois componentes indissociáveis: o meio 
natural e o meio cultural. Nas respostas dadas verifica-se claramente essa marcação da presença dos seres humanos nas relações com a natureza.

\subsection{Ambiente biocêntrico}

A natureza entendida como ambiente biocêntrico, como ambiente natural, rústico e primitivo, fonte de recursos para os humanos onde encontramos rios, animais, ar puro, plantas e florestas que formam um ecossistema natural que permite o equilíbrio e a contemplação dos humanos, cujos elementos naturais constituem esse espaço distinto do espaço dos humanos, é destacada por $36 \%$ dos/as professores/as. Essa compreensão de ambiente biocêntrico se caracteriza com presença abundante de elementos naturais e condições presentes nela, tais como "árvores, ar puro, área arborizada" e que implicam a não interferência humana pois são “... os elementos da natureza que ainda não sofreram alteração do homem". Esse entendimento, segundo Diegues (2011), está muito presente na sociedade vigente e tem como característica um mundo selvagem separado das pessoas e não próprio para elas.

\subsection{Ambiente restaurador}

Entre os/as professores/as, $20 \%$ deles entendem a natureza como um ambiente restaurador. Ambiente que promove bem-estar, saúde, tranquilidade e restauro do equilíbrio emocional. Inspirador de bons sentimentos e experiências vividas com suas paisagens e elementos naturais, cuja fonte de bem-estar promove sensações agradáveis pelo "ar saudável, tranquilidade, harmonia, equilíbrio, e convivência do ser humano com o ambiente natural". Contrário àqueles que distanciam a natureza, aqui fica estabelecida uma compreensão que requer sua proximidade devido aos sentimentos positivos advindos do contato que "me faz pensar em tranquilidade, saúde e harmonia". Alguns estudos têm demonstrado esse entendimento como fator preponderante nas experiências de contato direto com a natureza, uma vez que ela teria características promotoras de benefícios psicossociais (NISBET; ZELENSKY; MURPHY, 2011; WOLSKO; LINDEBERG, 2013).

\subsection{Ambiente divino}

Um grupo envolvendo 5\% dos participantes apresentou um entendimento da natureza como um ambiente divino, uma criação divina, algo perfeito que remete à existência e grandeza de um Deus, pela qual todos devem zelar. Uma criação que antecede aos humanos, “algo criado pelo Criador, aquilo que o homem já encontrou quando chegou”. A natureza seria a expressão da grandeza e da existência de um Deus, um presente divino aos humanos e que "na perfeição do senhor, e como isso, deve ser cuidado e zelado pelos seres viventes". A natureza relacionada à espiritualidade tem surgido como uma tendência contemporânea de sacralização (CARVALHO; STEIL, 2012) e como tal, o respeito se torna inexorável. 
Observa-se, portanto, que os/as professores/as concebem a natureza de múltiplas formas. Tal qual essas compreensões relativas à natureza, a conexão, ou afinidade emocional com a natureza, pode também se apresentar de maneira diferenciada entre os indivíduos. Vamos então, verificar quais os entendimentos de conexão com a natureza apontados pelos/as professores/as.

\section{Entendimentos de "estar conectado com a natureza"}

Na perspectiva evolucionista da biofilia, há uma tendência humana a perceber de maneira positiva a natureza e seus elementos que remetem a essa sensação de bem-estar, e, que por fim colocam o indivíduo em uma maior proximidade e em uma predisposição ao cuidado com a natureza (FEDRIZZI, 2011). A explicação evolucionista contida nessa proposta é de que os humanos obtiveram sistematicamente benefícios associados à natureza e que garantiram a sobrevivência da espécie como tal. Portanto, tal condição teria produzido seres com uma capacidade inata de afiliação com a natureza. Críticos a essa perspectiva defendem que esse fundamento genético não é suficiente, uma vez que seria necessário algum aprendizado sociocultural e vivências individuais relacionadas com ambientes naturais para uma efetiva tendência biofílica (KAHN, 1997; POOLEY; O’CONNOR, 2000).

Pesquisadores/as têm postulado que quanto maior os níveis de $\mathrm{CN}$, maior a satisfação pessoal e sensação de bem-estar (WOLSKO; LINDEBERG, 2013) e essa relação pode implicar sentimentos altruístas e comportamentos de cuidado ambiental (MAYER et al., 2009). No entanto, podemos questionar se essa natureza a que se refere, diz respeito a um ambiente físico ou simbólico que envolve acontecimentos sociais de outra ordem.

Observou-se que para os/as professores/as, esses aspectos da psicogênese e da sociogênese misturam-se na racionalidade do entendimento de estar conectado à natureza. Tais entendimentos foram agrupados em quatro categorias que expressam essa conexão como: (1) relação de proximidade com a natureza; (2) relação de cuidado com a natureza; (3) uso racional da natureza e, (4) conhecimento do funcionamento ecossistêmico. É possível observar a sistematização desses dados na Tabela 2. 
Tabela 2: Categorias de entendimento sobre $\mathrm{CN}$ e frequências

\begin{tabular}{l|c}
\hline \multicolumn{1}{c|}{ Categoria de entendimento sobre ligação/conexão com a natureza } & $\mathbf{N}$ \\
\hline $\begin{array}{l}\text { 1. Relação de proximidade com a natureza: Conexão como relação interdependente entre } \\
\text { seres humanos e natureza, estar em proximidade, intimidade e interação contínua com o } \\
\text { ambiente natural, respeitando e valorizando seus benefícios, se preocupando e se envolvendo } \\
\text { na sua manutenção para a sua preservação, harmonia e bem-estar humano. }\end{array}$ & 53 \\
\hline $\begin{array}{l}\text { 2. Relação de cuidado com a natureza: Conexão como cuidado com a natureza, de modo a } \\
\text { dar importância e respeitar os seus elementos naturais, cultivando e mantendo, não poluindo, } \\
\text { zelando e protegendo os recursos, vegetação e animais para o equilíbrio ambiental e garantia } \\
\text { de possibilidade dos recursos naturais para futuras gerações. }\end{array}$ & 28 \\
\hline $\begin{array}{l}\text { 3. Uso racional da natureza: Conexão como possibilidade de usufruir dos benefícios da } \\
\text { natureza para uma melhor qualidade de vida aos humanos. Ter consciência da dependência da } \\
\text { natureza, seus elementos e recursos para não prejudicar a existência do planeta. }\end{array}$ & 12 \\
\hline $\begin{array}{l}\text { 4. Conhecimento do funcionamento ecossistêmico: Conexão como conhecimento do } \\
\text { ecossistema e seu funcionamento, estando atento às mudanças que podem provocar problemas } \\
\text { ambientais e pôr em risco o planeta e a própria vida. }\end{array}$ & 7 \\
\hline \multicolumn{1}{c}{ TOTAL } & $\mathbf{1 0 0}$ \\
\hline
\end{tabular}

\subsection{Relação de proximidade com a natureza}

A conexão é entendida como relação interdependente entre seres humanos e natureza, estar em proximidade, intimidade e interação contínua com o ambiente natural, respeitando e valorizando seus benefícios, preocupando-se e envolvendo-se em sua manutenção para a sua preservação, harmonia e bem-estar. Essa categoria agrega as respostas de 53\% dos/as professores/as, que veem que na conexão com a natureza há intimidade e interação com o ambiente natural, de forma que "conviver de forma harmoniosa com a floresta e os animais, fazendo a minha parte procurando não poluir o meio ambiente”. Há nesse entendimento, o reconhecimento da necessidade de "estar em contato com a natureza, diretamente com os elementos que a compõem" para o equilíbrio e desenvolvimento humano e ambiental. Rocha e Mota (2011) destacam que tal relação é, ou deveria ser, uma relação positiva sem malefícios para ambas as partes.

\subsection{Relação de cuidado com a natureza}

Nesse mesmo caminho de relações, $28 \%$ dos/as professores/as atribuem o cuidado como a ideia subjacente ao termo conexão com a natureza. Caracterizada como cuidado com a natureza, de modo a dar importância e respeitar os seus elementos naturais, cultivando e 
mantendo, não poluindo, zelando e protegendo os recursos, vegetação e animais para o equilíbrio ambiental e garantia de possibilidade dos recursos naturais para futuras gerações.

Esse entendimento envolve "não poluir, não contribuir para o desmatamento e para o efeito estufa" e "sempre trabalhar para o bem da natureza e em consonância tratá-la com maior respeito e cuidá-la para o bem da humanidade".

Ao desenvolver tais ações de zelo pelos ambientes naturais e seus elementos, esses/as professores/as admitem existir uma postura de respeito que remete a uma afetividade benfeitora à natureza em si (BOFF, 2003), e uma preocupação com a disponibilidade dela para as gerações futuras (CORTEZ, 2011). Tais ações de cuidado referenciadas pelos/as professores/as remetem a valores e comportamentos ecológicos, tidos como ações em prol do ambiente, tendo em vista o uso sustentável dos recursos naturais (PATO; TAMAYO, 2006).

\subsection{Uso Racional da natureza}

Estar conectado com a natureza para um grupo de $12 \%$ dos participantes é uma maneira de uso racional da natureza. Conexão como possibilidade de usufruir dos seus benefícios para uma melhor qualidade de vida aos humanos. Use the "Insert Citation" button to add citations to this document.

Ter consciência da dependência da natureza, seus elementos e recursos para não prejudicar a existência do planeta.

Tal entendimento requer "estar envolvido com sua manutenção, ter cuidado para que ela não acabe e, dessa forma, usufruir dessa maravilha". Implica ainda em ter consciência da dependência humana diante da natureza e "não fazermos mal a ela, pois estaremos prejudicando a nós mesmos". De alguma forma esse entendimento de conexão com a natureza, deixa aparente um resquício do caráter utilitarista na ligação emocional, uma vez que ela seria fonte de matérias primas (ROCHA; MOTA, 2011). No entanto, a compreensão apresentada por esses/as professores/as mostra uma natureza a serviço da humanidade, bem como a implicação e o reconhecimento que as ações humanas podem trazer prejuízos ao ambiente. Por isso, eles destacam a necessidade do uso racional dos recursos naturais.

\subsection{Conhecimento do funcionamento ecossistêmico}

Para $7 \%$ dos/as professores/as, a conexão com a natureza é entendida como conhecimento do ecossistema e seu funcionamento, estando atento às mudanças que podem provocar problemas ambientais e pôr em risco o planeta e a própria vida. Desse modo "ter conhecimento sobre o que ocorre com o nosso ambiente" é da mesma forma "ter uma preocupação com ela. Saber o que acontece, tentar entender o seu processo". Assim estar conectado à ela seria ter conhecimento sobre o ecossistema, sobre os problemas ambientais, seus elementos constituintes e estar atento às mudanças na sua dinâmica que podem trazer riscos ao planeta. 
Essa compreensão se assemelha com as relações estabelecidas no início do movimento ecológico, quando o conhecimento científico foi ressaltado como passo importante na solução dos problemas ambientais (MARIANO et al., 2011). Ressalta-se, no entanto, que tal conhecimento, apesar de ser um caminho importante para gerar estratégias para a sua conservação, se configura como primordial para uma efetiva ligação emocional. Dessa maneira, a afetividade aparece como elemento central diante dos indicadores que revelam o entendimento de conexão com a natureza. Ainda que seja preciso considerar que essa afinidade direcionada a um ambiente, sempre reflete uma percepção ambiental a partir da experiência, sem descartar fatores como gênero, idade, aspectos históricos, sociais e geográficos (CHENG; MONROE, 2012; ROSA; ROAZZI; HIGUCHI, 2015; TUAN, 2012).

\section{Níveis de Afinidade Emocional com a Natureza entre os/as professores/as}

Este estudo corrobora com a afirmação de que os/as pesquisadores/as ainda enfrentam enormes desafios quando se propõem a medir aspectos afetivos e cognitivos para verificar o quanto eles estão implicados em posicionamentos direcionados à natureza (CHENG; MONROE, 2012). Isso se tornou evidente ao analisarmos os dados obtidos por meio do preenchimento da Escala de Conexão com a Natureza (ECN) e da Escala de Inserção da Natureza no Self (INS). Algumas considerações foram, no entanto, feitas para melhor eficácia e coerência do instrumento utilizado.

$\mathrm{Na}$ análise fatorial sem rotação foi indicada a retirada dos itens 3, 12, 13 e 14 da Escala de Conexão com a Natureza (ECN). O item 14, em particular, também foi excluído na versão recentemente adaptada para o contexto brasileiro por Pessoa e seus colegas (2016) e na versão adaptada para o contexto espanhol (PASCA et al., 2018; OLIVOS; ARAGONÉS; AMÉRIGO, 2011). Com um índice de $\mathrm{KMO}=0,809$, a escala demonstrou ser unifatorial após a retirada dos itens citados nessa amostra na região norte do Brasil. Observando-se os índices agrupados da ECN em um índice único e sua distribuição dentre os participantes da pesquisa, a média geral foi de 4,28 com desvio padrão de 0,48 . Tais valores indicaram alto grau de CN. Esses resultados corroboram o grande percentual $(81 \%)$ dos/as professores/as que possuem um entendimento de $\mathrm{CN}$ baseada nos aspectos de proximidade e de cuidado, isto é, em uma afetividade de base biocêntrica como mede a escala.

Verifica-se também que os mais altos índices no escore da ECN são, em grande parte, apresentados por aqueles/as professores/as que entendem a natureza como um ecossistema de relações. Nos cálculos de correlação de pontos bisseriais, essa categoria de entendimento apresentou fortes relações entre as duas variáveis diante da $\operatorname{ECN}(p=0,003 ; r=0,237)$. Outras variáveis também significativas para os graus na ECN foram o sexo e a área de formação. Os homens e os egressos das ciências da natureza (Ciências Biológicas, Ciências Naturais e Física) apresentaram índices altos, diferentemente das mulheres e daqueles com formação nas demais áreas de graduação que obtiveram baixos índices. A correlação com o sexo masculino obteve significância ( $p=0,025 ; r=0,183)$, bem como a correlação entre a ECN e a graduação na área de ciências da natureza $(p=0,013 ; r=0,203)$. 
Os resultados da Escala de Inserção da Natureza no Self (INS) mostraram que 62\% dos/as professores/as se consideram altamente conectados (as) com a natureza (entre os níveis cinco a sete), $26 \%$ se consideram conectados medianamente (níveis três e quatro) e $12 \%$ se consideram pouco conectados (níveis um e dois). Assim, verifica-se que os/as professores/as participantes da pesquisa se percebem com diferentes graus de afinidade emocional com a natureza, sentindo, em sua maioria, uma forte conexão com ela.

Os resultados das escalas (ECN e INS) mostraram-se correlacionados entre si. As pessoas que apresentaram altos escores na escala de INS, também apresentaram índices altos nas escalas de $\mathrm{ECN}(p=0,00 ; r=0,391)$. Os/as professores/as que manifestaram níveis mais altos de INS, isto é, dizem se sentir mais unidos à natureza, são também os que a entendem como um ecossistema de relações, semelhante ao que se observa com a ECN. Nas análises de correlação desse entendimento de natureza e da INS os resultados mostraram que assim como ocorreu com a ECN, o entendimento como ecossistema de relações está atrelado ao sentimento e à percepção dessa relação com a natureza de modo mais próximo $(p=0,020$; $r=0,190)$.

Os resultados mostram ainda que os/as professores/as com índices altos na escala INS são também aqueles que entendem a $\mathrm{CN}$ como uma forma de uso racional e cuidadoso dos elementos naturais. As análises de correlação entre as duas variáveis (grau de INS e entendimento de $\mathrm{CN}$ ) foram significativas ( $p=0,00 ; r=0,285)$. Portanto, os/as professores/as que se consideram mais fortemente ligados à natureza são também aqueles que entendem a importância de uma proximidade com ela baseada no uso racional de seus recursos e da manutenção de suas benfeitorias para o futuro.

A idade apresentou-se particularmente determinante dos níveis de INS. Os/as professores/as mais jovens ( 23 a 31 anos) foram os que apresentaram baixos índices de INS, diferentemente dos/as professores/as mais velhos (42 a 51 anos) que tiveram altos índices de INS, isto é, maior vínculo com a natureza. A correlação dessas duas variáveis (idade e índice de INS) mostrou-se inversamente significativa $(p=0,024 ; r=-0,184)$. Diante disso, pode-se inferir que os/as professores/as com mais idade são os que sentem maior afinidade com a natureza. O que pode estar associado a uma maior relação de apego com o ambiente natural (SOUSA et al., 2015).

Além da idade, semelhante ao que se observou com os dados da ECN, a área de formação se mostrou uma variável importante na explicação dos resultados da escala INS. Os/as professores/as com formação universitária na área de ciências da natureza são também os/as que demonstraram se sentir mais ligados à natureza, confirmada por uma relação significativa $(p=0,044 ; r=0,164)$. As demais áreas de graduação não apresentaram relações significativas com o INS, o que torna o conhecimento científico sobre as dinâmicas naturais um importante fator para mediar as relações com a natureza, assim como encontrado no estudo de Kapuderwan et al (2012). 


\section{Considerações Finais}

Compreender a dimensão afetiva das pessoas com os ambientes naturais, a partir do constructo da $\mathrm{CN}$, com agentes que exercem um fundamental papel de inspiração e formação de cidadãos/ãs, como os/as professores/as, se torna um fator relevante para problematizarmos o comportamento da sociedade diante da necessidade de proteção ambiental. O presente estudo mostra que o/a professor/a como agente de educação é detentor de entendimentos que podem invariavelmente estar subjacentes à afinidade emocional em relação à natureza, e que, em última instância estão associadas às suas práticas pedagógicas.

Nessa conjuntura, esse estudo corrobora resultados obtidos em outras pesquisas, no sentido de que os afetos devem ser entendidos não apenas como um aspecto avaliativo (cognitivo) da relação pessoa-ambiente, mas também como um aspecto indubitavelmente presente em toda ação humana. Assim revela, portanto, a unidade entre cognição e afetividade como forma de ampliação da consciência e como potencial de transformação dos laços de afinidade com a natureza.

Ao se compreender a natureza a partir de suas dimensões real e simbólica, racional e afetiva, puderam ser elencadas compreensões distintas desses/as professores/as. Significados compartilhados entre os grupos evidenciaram tanto os elementos físicos do ambiente natural quanto a relação das pessoas com esses cenários e os benefícios provenientes desse mundo natural. A natureza para esses/as professores/as não é necessariamente aquela apresentada pelas ciências ambientais, mas concebida como um mundo onde vários aspectos estão intimamente ligados e que estão subjacentes na relação que com ela se dá. Portanto, os resultados desse estudo nos permitem afirmar que, ao se enfatizar natureza, deve-se destacar que os entendimentos sobre ela irão, de alguma forma, interferir nas atitudes afetivas para com ela.

Além disso, o fato de os/as professores/as mostrarem entendimentos diferenciados do próprio constructo $\mathrm{CN}$ que expressa desde ações de proximidade e intimidade, de cuidado, de uso adequado ou até ter conhecimento profundo dela, pode indicar modos específicos de afinidade emocional para com o ambiente natural. No entanto, as análises indicaram que tais entendimentos não são necessariamente ligados, evidenciando que a construção desses significados não é linear. Em outras palavras, o entendimento de natureza não interfere no entendimento de $\mathrm{CN}$ e vice-versa.

Ao mensurar a afinidade emocional relativa à natureza entre os/as professores/as da educação básica utilizando-se das Escalas de Conexão com a Natureza (ECN) e de Inserção da Natureza no Self (INS), os índices foram positivamente altos. Ao contrário dos achados sobre a falta de correlação entre o entendimento de natureza e a conexão com a natureza, ao cruzarem-se com os níveis de afinidade emocional, as análises confirmaram haver associação entre o que os/as professores/as concebem ser natureza, e o que entendem por estar conectado com ela. Verificou-se ainda que variáveis como idade, gênero e área de formação universitária são determinantes nos graus de atitude afetiva em relação à natureza entre os/as professores/as. 
Diante dos problemas ambientais que requerem novas intervenções e adaptações humanas, os/as professores/as de todas as áreas de conhecimento também precisam estar sensibilizados para o cuidado com o ambiente. Ao conceberem natureza como fonte de elementos biofísicos que propiciam bem-estar aos seres humanos e necessária para a sua sobrevivência, os/as professores/as se tornam mais afetivamente ligados/as a ela. Da mesma forma, essa afinidade emocional está intimamente relacionada com uma formação na área de ciências da natureza.

Um dado preocupante refere-se aos/às professores/as mais jovens sem um curso de pósgraduação, pois foram aqueles que se mostraram menos afetivamente ligados com a natureza. Pode-se inferir que a formação complementar dos docentes pode contribuir para a construção de afetividades relacionadas aos ambientes naturais e consequentemente às ações que promovam a sua manutenção. Isto passa pelo seu reconhecimento como elemento crucial para a manutenção da vida no planeta e do papel dos/as professores/as da educação básica como estimuladores das reflexões acerca da relação pessoa-ambiente.

Embora ainda faltem informações mais precisas sobre a contribuição desta afinidade emocional ou $\mathrm{CN}$ e a prática docente, sabe-se que os/as professores/as têm um potencial importante de gerar impactos nas relações de cuidado ambiental e bem-estar físico e mental que seus alunos podem desenvolver. Assim, os/as professores/as tornam-se importantes agentes nos processos de construção dos sentimentos e dos conhecimentos necessários aos comportamentos de cuidado ambiental e melhoria da qualidade de vida.

Em que pese as contribuições desse estudo, algumas limitações devem ser pontuadas tais como a necessidade de um aprofundamento acerca de suas implicações na prática docente. Em estudos futuros sugere-se que haja investigações sobre: os fatores que contribuem para as ações educativas de maior aproximação e cuidado com o ambiente; a contribuição de formações continuadas para os/as professores/as em Educação Ambiental nas ações educativas nas escolas e, a implicação dos diferentes contextos escolares de modo transversal nestas ações em torno da afetividade ambiental.

\section{Nota}

1. Itens: 1) Muitas vezes me sinto unido à natureza ao meu redor; 2) Eu penso na natureza como uma comunidade da qual eu faço parte; 3) Eu reconheço e aprecio a inteligência dos outros seres vivos; 4) Frequentemente me sinto desconectado da natureza; 5) Quando eu penso na minha existência, eu me imagino como parte de um grande ciclo da vida; 6) Eu sinto uma identificação com as plantas e os animais; 7) Eu sinto que pertenço à Terra tanto quanto ela pertence a mim; 8) Eu tenho um entendimento claro de como minhas ações afetam à natureza; 9)Com frequência, me sinto parte da teia da vida; 10) Eu sinto que todos os habitantes da Terra, humanos e não humanos compartilham a mesma força vital; 11) Assim como uma árvore faz parte da floresta, eu me sinto parte da natureza; 12) Quando penso sobre o meu lugar na Terra, me considero no topo da hierarquia que existe na natureza; 13) Muitas vezes eu sinto que sou apenas uma pequena parte da natureza, e que não sou mais importante que a grama ou os pássaros; 14) Meu bem estar pessoal independe do bem-estar da natureza. 


\section{Referências}

ALBUQUERQUE, D.S.; SILVA, D. S.; KUHNEN, A. Preferências Ambientais e Possibilidades de Restauro Psicológico em Campi Universitários. Psicologia: Ciência e Profissão, v.36, n.4, p. 893-906, 2016. DOI: $10.1590 / 1982-3703002972015$

ALVES, S. M. Ambientes restauradores. In CAVALCANTE, S.; G. A. ELALI (Orgs.), Temas básicos em Psicologia Ambiental. Petrópolis/RJ: Vozes, 2011. p. 44-52.

BARDIN, L. Análise de Conteúdo. $3^{\text {a }}$ ed. Lisboa: Edições 70, 2004.

BAUER, M. W. Análise de Conteúdo Clássica: uma revisão. In BAUER, M. W.; G. GASKELL. Pesquisa qualitativa com texto, imagem e som. Trad. Pedrinho Guareschi. $8^{\text {a }}$ ed. Petrópolis/RJ: Vozes, 2010.

BOFF, L. Ética e Moral: a busca dos fundamentos. 2a ed. Petrópolis/RJ: Vozes, 2003.

BOMFIM, Z.A.C. Cidade e Afetividade: estima e construção de mapas afetivos de Barcelona e de São Paulo. Fortaleza: Editora da UFC, 2010.

BRANDÃO, I.R. Afetividade e transformação social. Sobral: Edições Universitárias, 2012.

CARVALHO, I.S.M.; STEIL, C.A. Cultura, Percepção e Ambiente - Diálogos com Tim Ingold. São Paulo: Terceiro Nome, 2012.

CARVALHO, I.C.M. A invenção do sujeito ecológico: sentidos e trajetórias em educação ambiental. Tese de Doutorado, Programa de Pós-Graduação em Educação, Universidade Federal do Rio Grande do Sul, Porto Alegre - RS, 2001.

CASTRO, P. Crenças e atitudes em relação ao ambiente e a natureza. In SOCKZA, L. (org.). Contextos humanos e psicologia ambiental. Lisboa, Portugal: Fundação Calouste Gulbenkian, 2005. p. 169-172.

CHAWLA, L. Childhood experiences associated with care for the natural world: a theoretical framework for empirical results. Children, Youth and Environments, v.17, n.4, p.144-170, 2007. DOI:10.7721/chilyoutenvi.17.4.0144

CHENG, J.C.H.; MONROE, M.C. Connection to Nature: Children's affective Attitude Toward Nature. Environment and Behavior. v.44, n.1, p.31-49, 2012. DOI: 10.177/0013916510385082

COELHO, F.; PEREIRA, M. C.; CRUZ, L.; SIMÕES, P.; BARATA, E. Affect and the adoption of proenvironmental behaviour: a structural model. Journal of Environmental Psychology, n.54, p. 127-138, 2017. DOI: 10.1016/j.jenvp.2017.10.008

CORTEZ, A.T.C. O lugar do homem na natureza. Revista do Departamento de Geografia - USP, n.22, p.2944, 2011. DOI: 10.1590/S0103-40142016.00100002

CORRAL-VERDUGO, V. Sustentabilidad y Psicologia Positiva: uma visión optmista de las conductas proambientales y prosociales. Mexico: Editorial el Manual Moderno, 2012.

CUNHA, D. C. Aspectos Cognitivos das Concepções sobre as Transformações de Áreas Verdes: A Floresta Amazônica em questão. Dissertação de Mestrado, Programa de Pós-Graduação em Psicologia Social, do Trabalho e das Organizações, Universidade de Brasília, Brasília-DF, 2010.

DAVIS, J. L.; GREEN, J.D.; REED, A. Interdependence with the environment: Commitment, interconnectedness, and environmental behavior. Journal of Environmental Psychology, v.29, n.2, p.173180, 2009. DOI: 10.1016/j.jenvp.2008.11.001

DIEGUES, C.A. O Mito Moderno da Natureza Intocada. $3^{\text {a }}$ ed. São Paulo: HUCITEC, 2011.

FAJERSZTAJN, L.; VERAS. M.; SALDIVA, P.H.N. Como as cidades podem favorecer ou dificultar a promoção da saúde de seus moradores? Estudos Avançados, v.30, n. 86, p.7-27, 2016.

FRANTZ, C. M.; MAYER, F. S. The importance of connection to nature in assessing environmental education programs. Studies in Educational Evaluation, n.41, p. 85-89, 2014. DOI: 10.1016/j.stueduc.2013.10.001 
FEDRIZZI, B. Biofilia e biofobia. In CAVALCANTE, S.; G. A. ELALI (Orgs.), Temas básicos em Psicologia Ambiental. Petrópolis/RJ: Vozes, 2011. p. 98-104.

FISHBEIN, M.; AJZEN, I. Belief, attitude, intention and behavior: An introduction to theory and research. Reading, Massachusetts: Addison-Wesley Publishing, 1975.

GIFFORD, R.; KORMOS, C.; MCINTYRE, A. Behavioral dimensions of climate change: drivers, responses, barriers, and interventions. Wiley Interdisciplinary Reviews: Climate Change, v.2, n.6, p.801-827, 2011. DOI: $10.1002 /$ wcc. 143 .

GRESSLER, S. C.; GÜNTHER, I.A. Ambientes restauradores: Definição, histórico, abordagens e pesquisas. Estudos de Psicologia, v.18, n.3, 2013.

GRESSLER, S. C. O descanso e a teoria dos ambientes restauradores. Tese de Doutorado, Programa de Pós-Graduação em Psicologia Social, do Trabalho e das Organizações, Universidade de Brasília, BrasíliaDF, 2014.

GUATARRI. F. As três ecologias. 11 a ed. Trad. Maria Cristina F. Bittencourt. Campinas, SP: Papirus, 2001.

GÜNTHER, H.; ELALI, G. A.; PINHEIRO, J. Q. Multimétodos. In CAVALCANTE, S.; G.A. ELALI (Orgs.), Temas Básicos em Psicologia Ambiental. Petrópolis/RJ: Vozes, 2011. p. 250-266.

GÜNTHER, I.A.; NEPOMUCENO, G.M.; SPEHAR, M.C.; GÜNTHER, H. Lugares favoritos de adolescentes no Distrito Federal. Estudos de Psicologia, v.8, n.3, p.299-308, 2003. DOI: 10.1590/S1413$294 X 2003000200012$

GÜNTHER, I.A.; FRAGELli, T.B.O. Estresse Ambiental. In CAVALCANTE, S.; ELALI, G.A. (Orgs.), Temas Básicos em Psicologia Ambiental. Petrópolis/RJ: Vozes, 2011. p. 191-197,

HIGUCHI, M.I.G.; KUHNEN, A.; BOMFIM, Z.A.C. Cognição Ambiental. In CAVALCANTE, S.; ELALI, G.A. (Orgs.), Temas Básicos em Psicologia. Petrópolis/RJ: Vozes, 2011. p. 105-121.

HUGHES, J.; RICHARDSON, M.; LUMBER, R. Evaluating connection to nature and the relationship with conservation behaviour in children. Journal for Nature Conservation, n.45, p.11-19, 2018. DOI: 10.1016/j.jnc.2018.07.004

IVES, C. D., GIUSTI, M., FISCHER, J., ABSON, D. J., KLANIECKI, K., DORNINGER, C., ...; RAYMOND, C. M. Human-nature connection: a multidisciplinary review. Current Opinion in Environmental Sustainability, n.26, p.106-113, 2017.

KAHN, P. H. Developmental psychology and the biophilia hypothesis: Children's affiliation with nature. Developmental Review, v.17, n.1, p.1-61, 1997. DOI: 10.1006/drev.1996.0430

KALS, E.; MAES, J. Sustainable development and emotions. Boston: Academic Publishers, 2008.

KAPURDEWAN, M.; ISMAIL, Z.; ROTH, W.M. Promoting pro-environmental attitudes and reported behaviors of Malasian pre-service teachers using green chemistry experiments. Environmental Education Research. v.18, n.3, p. 375-389, 2012

LIMA, L.M.P. A Influência dos Modelos Educacionais na Construção de Valores Sócio-Ambientais. Dissertação de Mestrado do Programa de Pós-Graduação em Desenvolvimento e Meio Ambiente PRODEMA. Universidade Federal de Pernambuco, Recife-PE, 2015.

LOUV, R. A última criança na natureza: resgatando nossas crianças do transtorno do déficit de natureza. 1a ed. São Paulo: Aquariana, 2016.

MARIANO, Z.F.; SCOPEL, I.; PEIXINHO, D.M.; SOUZA, M.B. A relação Homem-natureza e os discursos ambientais. Revista do Departamento de Geografia - USP, n.22, p.158-170, 2011. DOI: 10.7154/RDG.2011.0022.0008

MARTIN, C.; CZELLAR, S. Where do biospheric values come from? A connectedness to nature perspective. Journal of Environmental Psychology, n.52, p.56-68, 2017. DOI: 10.1016/j.jenvp.2017.04.009 
MAYER, F. S.; FRANTZ, C. M. The connectedness to nature scale: A measure of individuals' feeling in community with nature. Journal of Environmental Psychology, v.24, n.4, p.503-515, 2004. DOI: 10.1016/j.jenvp.2004.10.001

MAYER, S. F.; FRANTZ, C. M.; BRUEHLMAN-SENECAL, E.; DOLLIVER, K. Why is nature beneficial? The role of connectedness to nature. Environment and Behavior, n.41, p.607-643, 2009. DOI: 10.1177/0013916508319745

MERLEAU-PONTY, M. Fenomenologia da Percepção. São Paulo: Martins Fontes [1945], 1999.

MORIN, E. Introdução ao pensamento complexo. 5a . ed. Lisboa: Instituto Piaget, 2008.

MOURTHE JUNIOR, C. A.; LIMA, V. V.; PADILHA, R. Q. Integrando emoções e racionalidades para o desenvolvimento de competência nas metodologias ativas de aprendizagem. Interface (Botucatu), Botucatu, 2017.

NISBET, E. K.; ZELENSKI, J. M.; MURPHY, S. A. Happiness is in our nature: Exploring nature relatedness as a contributor to subjective well-being. Journal of Happiness Studies, n.12, p.303-322, 2011. DOI: 10.1007/s10902-010-9197-7.

OLIVOS, P.; ARAGONÉS, J. I.; AMÉRIGO, M. The connectedness to nature scale and its relationship with environmental beliefs and identity. International Journal of Hispanic Psychology, v.4, n. 1, p.5-19, 2011.

OTTO, S.; PENSINI, P. Nature-based environmental education of children: Environmental knowledge and connectedness to nature, together, and related to ecological behaviour. Global Environmental Change, v.47, p.88-94, 2017. DOI: 10.1016/j.gloenvcha.2017.09.009

PASCA, L.; COELlO, M. T.; ARAGONES, J.; FRANTZ, C. M. The equivalence of measures on the Connectedness to Nature Scale: A comparison between ordinal methods of DIF detection. PLos ONE, v.13, n.11, 2018. DOI: 10.1371/journal.pone.02077 39

PATO, C. M. L.; TAMAYO, A. A escala de comportamento ecológico: desenvolvimento e validação de um instrumento de medida. Estudos de Psicologia, v.11, n.3, p.289-296, 2006. DOI: 10.1590/S1413294X2006000300006

PERRIN, J.L.; BENASSI, V.A. The connectedness to nature scale: a measure of emotional connection to nature? Journal of Environmental Psychology, v.29, n.4, p.434-440, 2009. DOI: 10.1016/j.jenvp.2009.03.003

PESSOA, V. S.; GOUVEIA, V. V.; SOARES, A. K. S.; VILAR, R.; FREIRES, L.A. Escala de conexão com a natureza: evidências psicométricas no contexto brasileiro. Estudos de Psicologia (Campinas), v.33, n.2, p.271-282, 2016. DOI: 10.1590/1982-02752016000200009

POOLEY, J. A.; O'CONNOR, M. Environmental education and attitudes: Emotions and beliefs are what is needed. Environment and Behavior, v.32, n.5, p.711-723, 2000. DOI: 10.1177/0013916500325007

ROCHA, A.M.; MOTA, J.E.A. Cultura e Natureza nas sociedades modernas: ensaio sobre as relações entre homem e natureza nas sociedades produtoras de mercadorias. GEOUSP: Espaço e tempo, n.30, p.150-158, 2011. DOI: 10.11606/issn.2179-0892.geousp.2011.74238

ROSA, D.C.C.B. Teorias sobre a floresta e funções de apego: um estudo sobre a relação das pessoas com a Amazônia. Tese de Doutorado em Psicologia Cognitiva, Universidade Federal de Pernambuco, Recife-PE, 2014.

ROSA, D.C.C.B.; ROAZZI, A.; HIGUCHI, M.I.G. Perfil de Afinidade Ecológica: Um Estudo sobre os Indicadores da Postura perante a Natureza. Revista Psico, v.46, n.1, p. 139-149, 2015. DOI: 10.15448/1980-8623.2015.1.17415

SALDIVA, P. Vida Urbana e Saúde: os desafios dos habitantes das metrópoles. Editora Contexto, 2018.

SCANNEL, L.; GIFFORD, R. Defining place attachment: A tripartite organizing framework. Journal of Environmental Psychology, n.30, p.1-10, 2010. DOI: 10.1016/j.jenvp.2009.09.006 
SCHULTZ, P. W. The structure of environmental concern: Concern for self, other people, and the biosphere. Journal of Environmental Psychology, n.21, p.327-339, 2001. DOI: 10.1006/jevp.2001.0227

SOUSA, A. L.; MEDEIROS, J. S.; ALBUQUERQUE, D. S.; HIGUCHI, M. I. G. Parque Verde Urbano como espaço de desenvolvimento psicossocial e sensibilização socioambiental. Revista Psico, v.46, n.3, p.301310, 2015. DOI: 10.15448/1980-8623.2015.3.17423

STERN, P.; DEITZ, T. The value basis of environmental concern. Journal of Social Issues, v.50, n.3, p.65-84, 1994. DOI: $10.1111 / \mathrm{j} .1540-4560.1994 . t b 02420 . x$

THOMPSON, S. C. G.; BARTON, M. A. Ecocentric and anthropocentric attitudes toward the environment. Journal of Environmental Psychology, n.14, p.149-157, 1994. DOI: 10.1016/S0272-4944(05)80168-9

TOLEDO, R.F.; PELICIONI, M.C.F. A educação ambiental nos parques estaduais paulistas no âmbito das recomendações de Tbilisi. Revista Práxis Educativa, v.1, n.2, p.57-64, 2006. ISSN (online): 1809-4309

TUAN, Y. Topofilia: um estudo da percepção, atitudes e valores do meio ambiente. Trad. Lívia de Oliveira. Londrina: Eduel, 2012.

VERISSIMO, D.S. Considerações sobre corporeidade e percepção no último Merleau-Ponty. Estudos de Psicologia (Natal), v.18, n.4, p. 599-607, 2013. ISSN (online): 1678-4669

WOLSKO, C.; LINDBERG, K. Experiencing Connection with Nature: The Matriz of Psychological WellBeing, Mindfulness, and Outdoor Recreation. Ecopsychology, v.5, n.2, p.80-91, 2013. DOI: 10.1089/eco.2013.0008

\section{Correspondência}

Damaris Teixeira Paz: É Mestra em Ciências do Ambiente e Sustentabilidade na Amazônia; Colaboradora do Laboratório de Psicologia e Educação Ambiental do Instituto Nacional de Pesquisas da Amazônia.

E-mail: damaris.edu.paz@gmail.com

Maria Inês Gasparetto Higuchi: É Pesquisadora Titular do Instituto Nacional de Pesquisas da Amazônia, Coordenadora do Laboratório de Psicologia e Educação Ambiental.

E-mail: higuchi.mig@ gmail.com

Dayse da Silva Albuquerque: É Doutoranda em Psicologia da Universidade de Brasília (PSTO-UNB), Colaboradora do Laboratório de Psicologia e Educação Ambiental do Instituto Nacional de Pesquisas da Amazônia.

E-mail: albuquerque.miss@gmail.com

Adria de Lima Sousa: É Doutoranda em Psicologia - UFSC; Colaboradora do Laboratório de Psicologia e Educação Ambiental.

E-mail: adriapsique@gmail.com

Antonio Roazzi: É Professor do Departamento de Psicologia da Universidade Federal de Pernambuco.

E-mail: roazzi@gmail.com

Texto publicado em Currículo sem Fronteiras com autorização dos autores 